\title{
TEACHING ANATOMY USING (ONE-MINUTE PRECEPTOR) OMP IN COMBINATION WITH SPOTTING: RE-SHAPING THE SUBJECT.
}

1. MBBS, M.Phil, MHPE Associate Professor Anatomy Islam Medical College, Sialkot.

2. MBBS, FCPS

Professor Anatomy

Al Nafees Medical College, ISRA University.

3. MBBS, M.Phil

Assistant Professor Anatomy

Fazaia Medical College, Air

University.

4. MBBS, FCPS

Assistant Professor Physiology

Margalla Institute of Health

Sciences, Rawalpindi.

5. MBBS, M.Phil

Associate Professor Biochemistry Al Nafees Medical College, ISRA University.

6. MBBS, FCPS

Assistant Professor Anatomy

Army Medical College, Rawalpindi.

Correspondence Address:

Dr. Naureen Waseem

Department of Anatomy

Islam Medical College, Sialkot.

naureenwaseem82@gmail.com

Article received on:

28/03/2019

Accepted for publication:

$27 / 08 / 2019$
Naureen Waseem 1 , Khadija Iqbal ${ }^{2}$, Hina Kundi ${ }^{3}$, Irum Rehman ${ }^{4}$, Naveeda Zaigham ${ }^{5}$, Abdullah Qamar6

ABSTRACT... Objectives: The study determines the possible advantages of using the OMP in the gross anatomy laboratory. Study Design: Randomized Control Trial. Setting: Department of Anatomy Islam Medical College, Sialkot. Period: January 2018 to June 2018. Material \& Methods: 100 First year students of Islam Medical College were involved in the study. Two groups of 50 students each were made. Group 1 was exposed to the methodology of spotting. Students of group 2 were taught with One Minute Preceptor Model, but were allowed to do spotting/ structure identification themselves. Both groups were exposed to the same practical exam at the end of the course. Means of achieved marks and numbers of failures and passes were compared. All Statistical tests were applied using SPSS Version 20. Students were also asked to fill a questionnaire to find out students perception regarding the superiority of one teaching tool over the other. Results: The post hoc analysis of the result was done. The means of overall collective marks obtained by students of group I were insignificant when compared with the same of group II. Comparison of students on the basis of the passing status, carried out using Chi Square test also showed insignificant difference. On the other hand, from the questionnaires it was observed that active knowledge construction was more with OMP tool as compared to spotting. Understanding level was superior with OMP. Preparation for clinical teaching was also better with a combination of both as compared to spotting only and OMP. Conclusions: The one minute preceptor (OMP) is a time efficient teaching technique for learner centered training. It is a technique which can help the anatomy teachers to convert structure identification questions into active learning opportunities for learners. Teaching Anatomy using OMP in combination with spotting is a better tool in reshaping the subject.

Key words: Learner Centered Teaching, One Minute Preceptor, Spotting, Structure Identification, Teaching Technique.

Article Citation: Waseem N, Iqbal K, Kundi H, Rehman I, Zaigham N, Qamar A. Teaching anatomy using OMP in combination with spotting: Re-Shaping the subject. Professional Med J 2020; 27(4):730-736.

DOI: $10.29309 / \mathrm{TPMJ} / 2020.27 .04 .3460$

\section{INTRODUCTION}

Adequate knowledge of Anatomy, with strong emphasis on understanding rather than "knowing", and acquisition of essential anatomical skills such as power of identification, observation, identification and interpretational abilities, is considered crucial for safe and efficient clinical practice. ${ }^{1}$ The learning of anatomy by medical students is not only important for the attainment of essential, clinically based knowledge, but also for attainment of a range of skills. ${ }^{1}$

Anatomical knowledge is assessed by written and practical examinations. ${ }^{2}$ Written examination assess core knowledge of anatomy whereas the skills are assessed by practical examinations. The most common method for assessment of practical knowledge used in traditional curriculum is Spotting. Spotting examination constitutes a series of stations exhibiting cadaveric parts, dissections, plastinated models, microscopic slides, radiological images with arrows pins and tags pointing to specific structures. ${ }^{3}$ At each station, specific questions are then asked about where the pin is placed so as to identify the structure and a question may be asked related to that structure. ${ }^{4}$

The most common type of questions asked during gross practical examinations are the 
structure identification questions such as "What is the structure?" or "Identify A?" Students either just identify the structure or simply fail to apply the basic knowledge in identifying structures when confronted with the dissected specimens. ${ }^{5}$ Therefore it is required by the teachers to recognize the learning potential in these questions and turn them into active learning opportunities in limited available time. We must adopt a tool which appropriately tests students grasp of knowledge and believe it motivating, inspiring and interesting. ${ }^{6}$

Active learning is a learner centered teaching method in which the role of the teacher is to facilitate students learning. ${ }^{6}$ Students think through and find the answers to their own questions. Active learning is also an important component of adult learning theory according to which adults learn best by doing and by finding solution to their own problems. They learn from their own mistakes and building on their prior knowledge. ${ }^{6}$

So, gross anatomy teaching should move from a teacher centered to an active student centered style. The One Minute Preceptor (OMP) is an effective teaching method which can turn passive learning to active learner centered approach, and can turn structure identification questions into active learning opportunities. It can be modified according to learner need and context. ${ }^{7}$

One Minute Preceptor is a five step microskills model of clinical teaching. ${ }^{7}$ The One Minute Preceptor is a time efficient teaching strategy used in busy ambulatory setting to provide learners not only with new information but new ways of thinking without disruption of clinical care. OMP is much aligned with learner centered approach which includes fostering learners' responsibility in their own learning, creating appropriate motivation, actively involving in learning and emphasizing reflection and feedback in their learning. ${ }^{8}$ The technique consists of five simple steps called microskills which are: ${ }^{7}$

1. Getting a commitment

2. Probe for supporting evidence

3. Reinforce what was done right
4. Correct errors and fill in omissions

5. Teach a general rule

Variations can be made in the OMP technique for using it for Anatomy teaching, which is basically designed for clinical teaching..$^{9,10}$

$1^{\text {st }}$ Step- Getting a commitment is not important and may not be needed in anatomy as students know that one of the main tasks is to identify structures in cadaveric dissection.

$2^{\text {nd }}$ Step- Ask the students to give reasons for his or her identification of the structure. In this step a dialogue will start between a student and a teacher and the student will need to actively think and solve a problem in a comfortable environment without a fear of failing. Teacher simply want to know why the student think this in this step.

$3^{\text {rd }}$ Step- Reinforcing what was done right may be difficult in case of structure identification, because the identification cannot be practically right. Still any clue given rightly may emphasized to encourage students to say what they think in future teaching encounters.

$4^{\mathrm{TH}}$ Step- This step will involve explaining why the answer given or reasoning used by student was incorrect (if it was), identifying the structure and giving reasons for such identification.

$5^{\text {th }}$ Step- It involves teaching a general rule. The general principles in anatomy could be principles in identifying tissue type eg how to distinguish arteries, veins, nerves, tendons from each other, principles of identifying a longitudinal structure after identifying the tissue type (ie to trace the structure proximally and distally, to see its origins and terminations etc).

To introduce One Minute Preceptor in the gross anatomy teaching, we present an example for the OMP encounter.

Student: What is this? (Pointing to the brachial artery).

Preceptor: What do you think it is? (Getting a commitment).

Student: Call you give me some good reasons 
for calling this structure median nerve? (Probe for supporting evidence).

Preceptor: Well, it's a longitudinal structure in the anterior aspect of arm, and it looks like a nerve.

Preceptor: That's good. Median nerve is a longitudinal structure in the anterior aspect of arm. (Reinforce what was done right). But one thing you may want to consider further is the relationship of this structure with other similar structures in front of arm, and in cubital fossa. If it is the Median nerve, do you expect it to be on the just medial or the most medial side of Biceps tendon in the cubital fossa. (Guidance about errors and omissions).

Student: It would be the most medial structure in the cubital fossa.

Preceptor: Excellent! You just need to apply theory into practice here. This structure, just medial to the biceps tendon, is not likely to be Median nerve. If you trace it distally, you can see that it gets divided into two terminal branchesradial and ulnar arteries in the cubital fossa. Moreover it is rounder in cross section than a nerve. It is, therefore, more likely to be brachial artery. (Guidance about errors and omissions). In identifying a longitudinal structure, you must trace it proximally and distally to see where it comes from and where it goes. That helps you know what the structure is. Also, to distinguish an artery from a nerve, you can look at its cross sectional shape. (Teach a general rule). The main focus of the study is to explore the advantages of OMP when applied in gross anatomy teaching and observe the effects of this in cooperation in assessment.

\section{MATERIALS AND METHODS}

100 first year students of Islam Medical College, Sialkot session 2018-2022 were involved in this randomized control trial. Prior to the commencement of the study permission from academic and administrative authorities of the college was obtained. The study began at the start of tenure of second substage of upper limb. For the first substage all students have been introduced to cadaveric dissection with the help of spotting and one minute preceptor both.
The students were selected by non probability consecutive sampling. They were selected without prior knowledge of their results in previous substage. Two groups of 50 students each were made by randomly dividing the students. Group 1 was exposed to the methodology of spotting. The students did the structure identification themselves under supervision of demonstrators in the dissection hall. Students of group 2 were taught with One Minute Preceptor Model, but were allowed to do spotting/ structure identification themselves. Out of all the faculty members, two enthusiastic and competent demonstrators with same level of teaching skills were selected for this study. To minimize the associated bias, dissected regions groups were kept same for both groups; each demonstrator taught the practical skills to both groups with the methodology outlined for each group (group 1 was taught by spotting, while group 2 was facilitated with one minute preceptor).

The students of both groups were facilitated for half an hour daily to develop practical skills for fifteen days for completion of course, along with their regular gross anatomy demonstrations. Half an hour was consumed justifiably by both groups in practical work and facilitation of both by teachers. Both groups were exposed to the same practical exam at the end of the course. Practical examination included 10 stations of 2 marks each, of the course content taught by spotting and OMP in the last 15 days. The papers were checked by the teachers against structured key.

The results of both groups were recorded and means of achieved marks were calculated. Means of achieved marks were compared between two groups by independent sample t test. Students with $50 \%$ and above marks were declared pass as per the passing criteria laid by UHS. Numbers of failures and passes were compared by Chi Square test. All Statistical tests were applied using SPSS Version 20.

After the examinations, students were asked to fill a questionnaire to find out students perception regarding the superiority of one teaching tool over the other. It had five open ended questions 
each with four options to know which method was helpful in enhancing their cognition.

\section{RESULTS}

In group I forty six out of fifty students appeared while in group II forty nine students took the examinations. Total marks allocated were 20.

When the means of overall collective marks obtained by students of group I were compared with the same of group II, it showed insignificant statistical difference (Table-I).

Comparison of students on the basis of the passing status was carried out using Chi Square test. The obtained $P$ value of 0.73 showed insignificant statistical difference. (Table-II).

From all the filled questionnaires it was observed that active knowledge construction was more with OMP tool as compare to spotting. But a combination of both gave $70.5 \%$ results. Understanding level was superior $55 \%$ as compared to $28 \%$ with OMP and $14 \%$ with spotting. Help to recall and making learning interesting was also better with combination of both spotting and OMP (47.4\% and 48.4\%).Preparation for clinical teaching was also better with a combination of both as compared to spotting only $14.7 \%$ and OMP $31 \%$ (Table-III).

\section{DISCUSSION}

Learning of Anatomy with dissection and interaction with cadaveric specimens is very important for better apprehension of the structures. ${ }^{11}$ As the teaching environment of the gross anatomy laboratory is similar to ambulatory care setting, a potential strategy, the one- minute preceptor model, which was originally designed for busy clinics can be used for anatomy teaching. ${ }^{12}$

\begin{tabular}{|l|c|c|}
\hline \multicolumn{1}{|c|}{ Groups } & Means of marks \pm S.D. & $\square \square$ P Value \\
\hline $\mathrm{I}$ & $9.68 \pm 4.230$ & 0.565 \\
\hline $\mathrm{n}=46$ & $13.215 \pm 3.46$ & \\
$\mathrm{n}=49$ & & \\
\hline
\end{tabular}

Table-I. Means and statistical comparison of marks obtained by both groups

\begin{tabular}{|c|c|c|c|}
\hline Groups & Fail & $\begin{array}{l}\text { sing } S \\
\text { Pass }\end{array}$ & Total \\
\hline $\begin{array}{l}\mathrm{l} \\
\mathrm{n}=46\end{array}$ & 10 & 36 & 46 \\
\hline $\begin{array}{l}\text { II } \\
n=49\end{array}$ & 8 & 41 & 49 \\
\hline
\end{tabular}

Table-II. Performance of students on the basis of passing marks

\begin{tabular}{|c|c|c|c|c|}
\hline \multirow[b]{2}{*}{ Question } & \multicolumn{4}{|c|}{ Number of Responses } \\
\hline & Spotting & $\begin{array}{l}\text { One Minute } \\
\text { Preceptor }\end{array}$ & $\begin{array}{c}\text { Combination of } \\
\text { Both }\end{array}$ & None \\
\hline Superior tool of understanding & $14(14.7 \%)$ & $27(28.4 \%)$ & $53(55.8 \%)$ & $1(1.1 \%)$ \\
\hline Helps in recalling & $20(21.1 \%)$ & $28(29.5 \%)$ & $46(48.4 \%)$ & $1(1.1 \%)$ \\
\hline Prepares students for clinical Teaching & $14(14.7 \%)$ & $30(31.6 \%)$ & $50(52.6 \%)$ & $1(1.1 \%)$ \\
\hline
\end{tabular}


One minute preceptor model foster learners' responsibility for their own learning, emphasize on learners' reflection and feedback and customize the teaching activities in light of learners' level of knowledge. ${ }^{12}$

This study was designed keeping in view the in cooperation of active learning opportunities in anatomy teaching. The comparison of the overall performance and passing status of the two groups of students exposed to spotting and One Minute preceptor showed statistically insignificant results. There is no documentation of any previous research based on the same design. However a short communication has been documented highlighting the importance of One Minute Preceptor in Anatomy. As the OMP is based on adult learning principles, it should be useful for learning in other settings. ${ }^{9}$ Therefore in a study Chan and Wiseman (2011) proposed that OMP would prepare the students for clinical encounters and therefore could be adapted for gross anatomy teaching. ${ }^{9}$

In a study, Chan et al explored the effects of One Minute Preceptor technique by novice teachers in gross anatomy laboratory. He found that the novice teachers are more receptive to OMP than experienced teachers and OMP is useful for their development in teaching anatomy. ${ }^{10}$ The experienced teachers documented that they would have been benefited, if they were exposed to OMP model as novice teachers. ${ }^{13}$ In another research post graduate trainees who were trained to use OMP improved students' self confidence in the application of their knowledge and produced better learning outcomes in their students. ${ }^{14}$

The results of these previous studies and the current study endorse the fact OMP could be adapted as an teaching and assessment tool in anatomy. This can also go in line that one teacher needs to supervise several small groups in the dissection hall and the encounters are also brief. ${ }^{11}$ The comparison of the marks obtained by the two groups provided an interesting insight. The mean of the marks of the students facilitated by spotting were less than group II which was facilitated by One Minute Preceptor. The results of the current study suggest that OMP helps the students in the in-depth understanding of the structures and the application of theory into practice better than spotting. The students who are not exposed to OMP faced difficulty in achieving the same level of skills required in practical examination. All these skills need to be inculcated in future doctors right from their training in first year as they are essential for medical doctors. Chan and Wiseman, 2011 gave several reasons for OMP to be beneficial in anatomy as it actively engages the learner in problem solving and emphasize on learners' reflection as it fosters learners' responsibility for their own learning. ${ }^{9}$ The use of OMP has been studied in pharmacology and histopathology too showing better understanding and learning of students. ${ }^{15,16,17,18}$

Although the students of each group were taught by one methodology during this study, they were exposed to both strategies during the tenure of first substage. So they could comment on the effectiveness of the tool when they were inquired through the questionnaire. In this study, when a questionnaire was given to discern the perception of students towards a particular teaching methodology, majority of the students mentioned that a combination of both tools will improve various aspects of learning gross anatomy. Anatomy teaching has transformed enormously in the last decade during which a variety of teaching and learning strategies have emerged as a replacement of conventional with modern teaching tools. ${ }^{19}$

The potential advantages of OMP in the gross anatomy laboratory as per the students responses were that OMP encourages active learner centered learning more in comparison to spotting. Then it prepares students for clinical teaching..$^{20}$ The use of OMP early in anatomy may prepare students to "learn how to learn" in clinical settings. OMP provides immediate feedback to the students on their learning, so they gain confidence from the praise and learn from their mistakes which made their learning interesting. ${ }^{21}$ The OMP enables teachers to adapt to the individual learners needs making it a superior tool of understanding. It allows the teacher to motivate the students and 
solve the problems on their own, which made their learning interesting. ${ }^{22}$

\section{CONCLUSION}

The one minute preceptor (OMP) is an efficient teaching technique for learner centered training. There are possible advantages of using the OMP in the gross anatomy as it converts "What is this?" in the gross anatomy teaching to "I think this is X because.....". It focuses on application of knowledge rather than mere structure identification of structures. OMP is a technique which can help the anatomy teachers to convert structure identification questions into active learning opportunities for learners. Teaching Anatomy using OMP in combination with spotting is a better tool in reshaping the subject.

\section{Copyright@ 27 Aug, 2019.}

\section{REFERENCES}

1. Abu-Hijleh M, Chakravarty N, Latif M, Osman A, Salem R, Fadel and A. Dharap. 2009. The place of Anatomy in Medical Education, Amee guide supplement 41.2

2. Drake RL, McBride JM, Lachman N, Pawlina W. Medical education in the anatomical sciences: The winds of change continue to blow. Anatomical sciences education. 2009 Nov 1; 2(6):253-9.

3. Sugand $K$, Abrahams $P$, Khurana $A$. The anatomy of anatomy: A review for its modernization. Anatomical sciences education. 2010 Mar 1; 3(2):83-93.

4. Zafar M, Yaqinuddin A, Ikram F, Ganguly P. Practical examinations-OSPE, OSCE and SPOT.

5. Chan LK, Ganguly PK. Evaluation of small-group teaching in human gross anatomy in a Caribbean medical school. Anatomical sciences education. 2008 Jan; 1(1):19-22.

6. Kaufman DM. Applying educational theory in practice. Bmj. 2003 Jan 25; 326(7382):213-6.

7. Neher JO, Stevens NG. The one-minute preceptor: Shaping the teaching conversation. FAMILY MEDICINE-KANSAS CITY-. 2003 Jun 1; 35(6):391-3.

8. Wall D. The straight facts no nonsense teacher. Your Teaching Style: A Practical Guide to Understanding, Developing and Improving. 2008:53-60.

9. Chan LK, Wiseman J. Use of the one-minute preceptor as a teaching tool in the gross anatomy laboratory. Anatomical sciences education. $2011 \mathrm{Jul}$ 1; 4(4):235-8.
10. Chan LK, Yang J, Irby DM. Application of the one $\square$ minute preceptor technique by novice teachers in the gross anatomy laboratory. Anatomical sciences education. 2015 Nov 12; 8(6):539-46

11. McLachlan JC, Patten D. Anatomy teaching: Ghosts of the past, present and future. Medical education. 2006 Mar; 40(3):243-53.

12. Chan LK. Promoting reflection in the laboratory. InTeaching Anatomy 2015 (pp. 203-211). Springer, Cham.

13. Chan LK, Sharma N. Effects of training experienced teachers in the use of the one-minute preceptor technique in the gross anatomy laboratory. Anatomical sciences education. 2014 Mar; 7(2):124-9.

14. Salerno SM, O'malley PG, Pangaro LN, Wheeler GA, Moores LK, Jackson JL. Faculty development seminars based on the one-minute preceptor improve feedback in the ambulatory setting. Journal of general internal medicine. 2002 Oct 1; 17(10):779-87.

15. Neher JO, Stevens NG. The one-minute preceptor: Shaping the teaching conversation. FAMILY MEDICINE-KANSAS CITY-. 2003 Jun 1; 35(6):391-3.

16. Drake RL, McBride JM, Lachman N, Pawlina W. Medical education in the anatomical sciences: The winds of change continue to blow. Anatomical sciences education. 2009 Nov 1; 2(6):253-9.

17. Chandra S, Ahsan M, Chandra S, Shaifali I, Koul R. Effect of one minute preceptor (OMP) model in learning of core competencies in Pharmacology. Journal of Education Technology in Health Sciences. 2018 Mar 30; 5(1):49-56.

18. Gulati HK. One minute preceptor-Introduction and perception evaluation of a novel teaching tool for teaching routine histopathology slides to postgraduate students in pathology. Indian Journal of Pathology and Oncology. 2016; 3(3):503-7Chan LK. Promoting reflection in the laboratory. In Teaching Anatomy 2015 (pp. 203-211). Springer, Cham.

20. Teherani A, O'Sullivan P, Aagaard EM, Morrison EH, Irby DM. Student perceptions of the one minute preceptor and traditional preceptor models. Medical teacher. 2007 Jan 1; 29(4):323-7.

21. Pawlina W, Drake RL. Driving effective communication through anatomy. Anatomical sciences education. 2008 Mar; 1(2):49-. 
22. Conn JJ, Lake FR, McColl GJ, Bilszta JL, WoodwardKron R. Clinical teaching and learning: from theory and research to application. Med J Aust. 2012 May 7; 196(8):527.
23. Aagaard E, Teherani A, Irby DM. Effectiveness of the one-minute preceptor model for diagnosing the patient and the learner: proof of concept. Academic Medicine. 2004 Jan 1; 79(1):42-9.

\section{AUTHORSHIP AND CONTRIBUTION DECLARATION}

\begin{tabular}{|c|c|c|c|}
\hline Sr. \# & Author(s) Full Name & Contribution to the paper & Author(s) Signature \\
\hline 1 & Naureen Waseem & $\begin{array}{l}\text { Conception or design of the work or the acquisition, } \\
\text { analysis or interpretation of data for the work. } \\
\text { Drafting the work or revising it critically for important } \\
\text { intellectual content. }\end{array}$ & 1 \\
\hline 2 & Khadija Iqbal & $\begin{array}{l}\text { Conception or design of the work or the acquisition, } \\
\text { analysis, or interpretation of data for the work. }\end{array}$ & Khadije \\
\hline 3 & Hina Kundi & $\begin{array}{l}\text { Interpretation of data and statistical } \\
\text { analysis. }\end{array}$ & \\
\hline 4 & Irum Rehman & $\begin{array}{l}\text { Drafting the work and revising it } \\
\text { critically, Manuscript preparation, } \\
\text { editina in review. }\end{array}$ & Iuvalehmary. \\
\hline 5 & Naveeda Zaigham & $\begin{array}{l}\text { Interpretation of data ana statistical } \\
\text { analysis, Manuscript preparation, }\end{array}$ & Mhudedozoingan \\
\hline 6 & Abdullah Qamar & $\begin{array}{l}\text { editing in review. } \\
\text { Interpretation of data and statistical } \\
\text { analysis, Drafting and proof reading } \\
\text { of article. }\end{array}$ & Abrolloh onas \\
\hline
\end{tabular}

